\title{
Theoretical comparison of low GWP alternatives for different refrigeration configurations taking R404A as baseline
}

\author{
Adrián Mota-Babiloni ${ }^{\mathrm{a}, \mathrm{b}}$, Joaquín Navarro-Esbrí ${ }^{\mathrm{b}, *}$, Ángel Barragán ${ }^{\mathrm{b}}$, Francisco Molés ${ }^{\mathrm{b}}$, \\ Bernardo Peris ${ }^{\mathrm{b}}$ \\ a Institute for Industrial, Radiophysical and Environmental Safety, Camino de Vera s/n, \\ Polytechnic University of Valencia, E-46022 Valencia, Spain. \\ ${ }^{\mathrm{b}}$ ISTENER Research Group. Department of Mechanical Engineering and Construction, \\ Campus de Riu Sec s/n, University Jaume I, E12071, Castellón, Spain.
}

\begin{abstract}
Six refrigerants are evaluated as low GWP replacements for R404A using different configurations, including two-stage system architectures. These refrigerants are selected according to similar characteristics to R404A, and they are the mid-term alternatives R407A and R407F, and the long-term alternatives: L40 and DR-7 (with very low GWP and low flammability), N40 and DR-33 (with low GWP and no flammability). In order to have a complete comparison range, various operating conditions are considered, covering low and medium evaporator temperatures and two levels of condensation temperatures. Configurations selected are presented and the equations used to simulate the expected performance are shown. From a given cooling capacity, volumetric flow rate and COP are compared, taking R404A as baseline. The most efficient alternatives are the low-flammable refrigerants, L40 and DR-7, and when no flammability is acceptable, N40 and DR-33 are also very good options.
\end{abstract}

Keywords: refrigeration; configurations; R404A replacements; GWP; Coefficient of Performance.

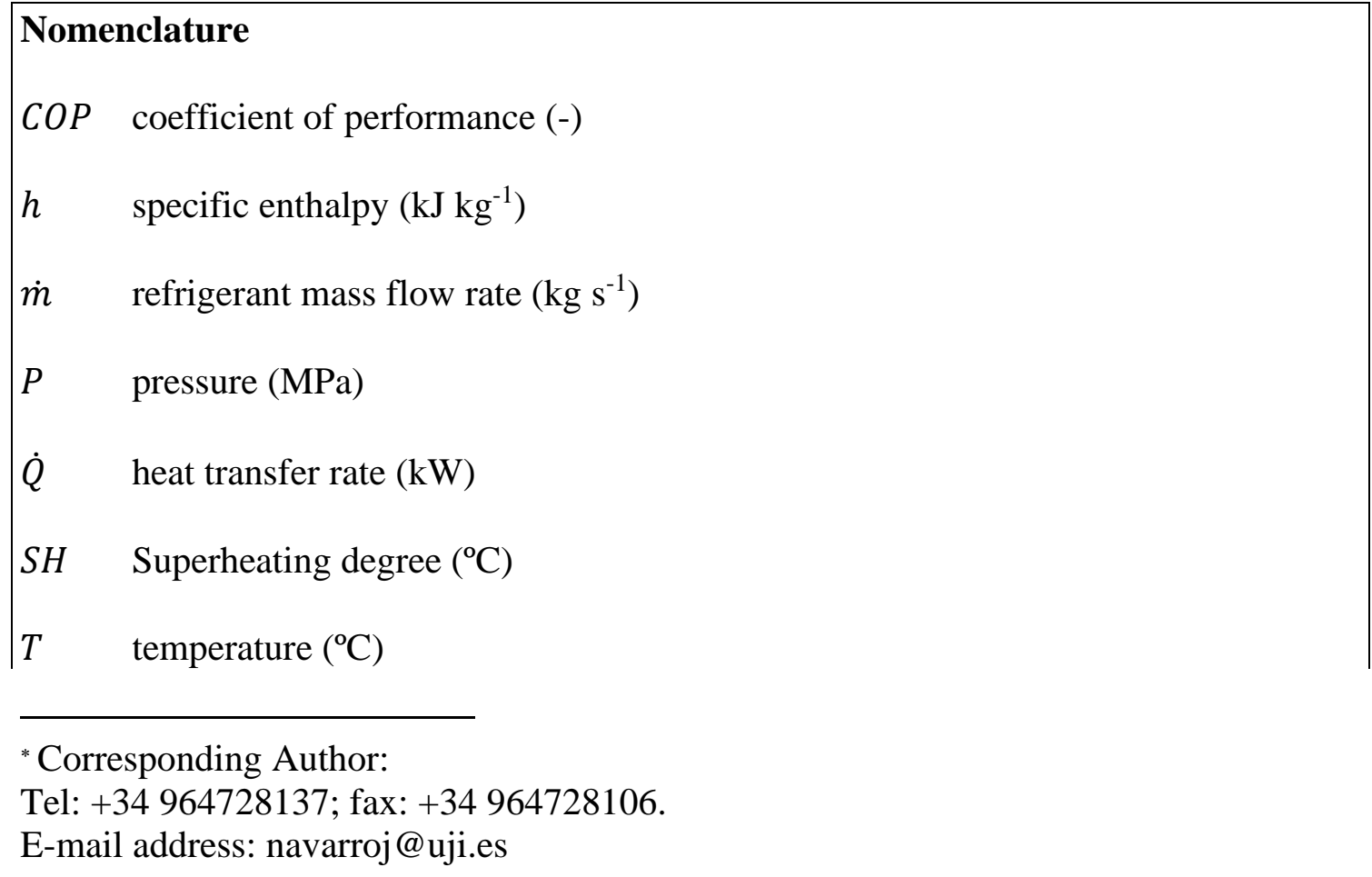


$\dot{V} \quad$ volumetric flow rate $\left(\mathrm{m}^{3} \mathrm{~s}^{-1}\right)$

$\dot{W}_{c} \quad$ compressor power consumption $(\mathrm{kW})$

Greek symbols

$\varepsilon \quad$ effectiveness

$\eta \quad$ efficiency

$\rho \quad$ density $\left(\mathrm{kg} \mathrm{m}^{-3}\right)$

Subscripts

disc discharge

HP high pressure stage

IHX Intermediate Heat Exchanger

in inlet

IP intermediate pressure stage

$k \quad$ condenser

liq saturated liquid

LP low pressure stage

out outlet

suc suction

SC subcooler

o evaporator

\section{Introduction}

To avoid the reduction in the atmospheric ozone, according to the terms of the Montreal Protocol, a total phase-out for chlorofluorocarbon (CFC) by 2010 and hydrochlorofluorcarbon (HCFC) by 2040 in all countries [1] has been established. In this way, hydrofluorocarbon (HFC) gases became relevant in all refrigeration fields [2] because of their zero Ozone Depletion Potential (ODP). And while they are non-ozone depleting substances, they have great values of global warming potential (GWP). So, after being approved the Kyoto Protocol in 1997 [3], HFC refrigerants were considered as greenhouse gases (GHGs) and they would be progressively removed. 
Through the European Directive 2006/40/EC [4] fluids with GWP>150 are banned for new mobile air conditioners (MAC) since 2011 and for the rest MAC systems will be excluded onward 2017. Additionally, in 2012 a tightening of the F-gas regulation was proposed, where a reduction reaching $21 \%$ of the levels sold in 2008-2011 by 2030 is established. In this way, in 2013 in Spain, a tax focused on refrigerants with high GWP [5] was also approved.

So, because of the relevance of the refrigerant gas leakages from vapour compression systems (in UK supermarkets around 13\% of refrigerant from circuits is lost [6]), research efforts in the refrigeration industry are focused on finding non-toxic fluids with low GWP and with low flammability to replace high GWP working fluids used in existing vapour compression cycles [7].

Analyzing low and medium temperature commercial refrigeration applications, due to Montreal Protocol, there was a retrofit process from R22 and R502 to zero-ODP refrigerants, mainly R134a, R404A and R507A [8, 9]. R404A and R507A are very similar and they can be used both for a very wide range of evaporation temperatures, R404A being mostly used in Europe. R404A shows excellent properties: nonflammable and non-toxic, easy retrofit in R22 systems, a similar range of operating conditions and presents good energy efficiencies [10-14]. However, R404A presents high GWP (3922) [15] and probably is going to be phase-out over the next years [16].

Currently, HFC mixtures are prevailing as medium GWP replacements for R404A. In this way, non-flammable mid-term solutions like R407A (GWP=2107) or R407F $(\mathrm{GWP}=1825)$ are available $[17,18]$. Despite having half the GWP of R404A, these refrigerants are presented with a better performance in light retrofit processes. In order to work with refrigerants with even lower GWP values, long-term solutions are being developed by Honeywell (Solstice ${ }^{\mathrm{TM}}$ N40 and L40) [19] or DuPont (DR-7 and DR-33) [20], developing HFC and HFO blends.

While N40 and DR-33 are non-flammable refrigerants with relatively low GWP values (1205 and 1410, respectively), L40 and DR-7 have a low GWP (285 and 246, respectively) even though they would be classified as A2L by ASHRAE Standard 34 [21]. Yana Motta et al [22] suggest using in future studies flammable refrigerants in high side of secondary fluid systems (chillers), cascade systems $\left(\mathrm{CO}_{2}\right.$ in the low stage), small close-coupled systems, and even distributed systems.

Moreover, Yana Motta et al [22] tested low GWP refrigerants (R407F, N40, N20 and L40) in a refrigeration system designed for R404A. All alternatives showed superior performance, acceptable pressures and discharge temperatures below the limits. On the other hand, they recommended some changes when using flammable refrigerants. Minor et al [20] experimented with DR-7 and DR-33 in a double-door unit designed for R-404A. The conclusions were that both replacements presented similar (DR-33) or slightly minor (DR-7) energy consumption, similar pressures and compression ratio, and the increase in discharge temperature was about $13-16^{\circ} \mathrm{C}$.

Besides using low GWP alternatives, it is also important to look for more efficient systems. In this way, applying some modifications to the basic cycle [23] should be considered. For example, the refrigerating effect in the evaporator can be enhanced 
using an internal heat exchanger (IHX) [24]. By introducing an ejector expansion cycle an increment in COP parameter can be achieved [25], or expanders can even be consider to reduce system energy consumption thanks to expansion work recovery [26]. With two-stage systems, several configurations can be taken into account by the introduction of a flash tank or a subcooler at the intermediate stage or injecting a mixture of liquid and vapour in the discharge of the low pressure compressor [27] or even applying modifications of one-stage system as an IHX and/or an ejector [28]. It has been demonstrated that although the systems developed are more complex, higher efficiencies can be reached and discharge temperature considerably reduced by allowing cycles working at higher compression rates.

Therefore, the aim of this work is to compare theoretically the energy performance of four vapour compression refrigeration configurations using R404A and low GWP refrigerants R407A, R407F, L40, DR-7, N40 and DR-33 as alternative fluids. This paper is organised as follows: In Section 2, the main properties of the chosen working fluids are exposed. In Section 3, the proposed configurations are presented. In Section 4, the equations used to obtain the expected performance are introduced. In Section 5, the results are shown and discussed. Finally, Section 6 summarizes the main conclusions of the work.

\section{Working fluids}

As said before, this study focuses on comparing R404A with low GWP alternatives. The refrigerants finally selected refrigerants also have to accomplish other characteristics as thermal stability, low flammability and low toxicity. Furthermore, when those alternative refrigerants have to be retrofitted into a R404A vapour compression plant, similar working conditions to R404A and oil compatibility are required. The selected refrigerants are classified as commercial mid-term alternatives (medium GWP), R407A and R407F, and long-term alternatives, refrigerants that are being developed nowadays. Long-term alternatives are sub-classified as flammable refrigerants (very low GWP), L40 and DR-7, and non-flammable refrigerants (medium low GWP), N40 and DR-33.

First, in Table 1, main characteristics of the selected refrigerants are summarised, taking R407A [17] and R407F [18] as R404A mid-term replacements, Honeywell L40 and N40 [19], Dupont DR-7 and DR-33 [20] as long-term alternatives. It can be seen that alternative refrigerants show similar properties to R404A, and the following conclusions can be extracted when they are compared with R404A:

- Similar boiling point, with the exception of DR-7 that has an approximately $3^{\circ} \mathrm{C}$ higher.

- Higher critical temperature: approx. 15\% higher for R407A, R407F, N40 and DR-33; $21 \%$ greater L40 and 4\% smaller for DR-7.

- Higher critical Pressure: from 15\% for DR-33 up to $27 \%$ for L40.

- The replacements have a higher glide value that makes this effect non depreciable when configurations with a flash tank are considered. From $5^{\circ} \mathrm{C}$ for DR-7 up to $7.7^{\circ} \mathrm{C}$ for L40.

- All the alternatives provide important GWP reductions. 
Table 1. Characteristics of refrigerants selected [17-20].

\section{Configurations selected}

In this paper four vapour-compression configurations are considered: Basic cycle (BC), Basic cycle with Internal Heat Exchanger (BCIHX), Direct Injection (DI) and Subcooler Cycle (SC).

The first configuration presented is Basic cycle, Fig. 1.a). It consists of the basic elements: condenser, expansion valve, evaporator and compressor. Modifying this configuration the other configurations analysed in this work are obtained.

Fig. 1.a) Diagram and P-h cycle of configurations. Basic Cycle.

Basic cycle with IHX configuration is achieved by adding a heat exchanger between the suction and the liquid line, Fig. 1.b). Cooling the liquid line, the refrigerant entering in the evaporator has a lower enthalpy, and the refrigerating effect in it is greater. On the other hand, suction gas is heated causing higher gas discharge temperature; besides compressor consumption is increased. Finally, the COP variation could be positive or negative, depending on the studied refrigerant.

Fig. 1.b) Diagram and P-h cycle of configurations. Basic Cycle with IHX.

The introduction of two-stage cycles reports an increase in the cycle efficiency and decrease the discharge temperature. Another consequence is the increment in the mass flow rate in the high-pressure stage compressor. It must be noted that those configurations with flash tank are not considered in this work due to the high glide presented by the alternative refrigerants analyzed.

By injecting refrigerant at intermediate pressure in the discharge of the low pressure compressor the Direct Injection configuration can be obtained, Fig. 1.c).

Fig. 1.c) Diagram and P-h cycle of configurations. Direct Injection.

Finally, Subcooler Cycle configuration is the more complex configuration analysed, in terms of construction. It is brought off using a heat exchanger (subcooler) that uses a part of refrigerant derived at intermediate pressure to cool the rest of liquid refrigerant, Fig. 1.d). Then refrigerant at an intermediate pressure is mixed with the discharge gas of the low pressure compressor. A higher refrigerating effect at the evaporator stage is reached and the discharge temperature is reduced. 
Fig. 1.d) Diagram and P-h cycle of configurations. Subcooler Cycle.

\section{Simulation conditions and equations applied}

In order to model the vapour compression cycle for each configuration, two parameters are combined trying to simulate working conditions (taking into account glide considerations [29]):

- Average evaporation temperature, $T_{o}:-40^{\circ} \mathrm{C}$ (low evaporation temperature) and $10^{\circ} \mathrm{C}$ (medium evaporation temperature).

- Average condensation temperature, $T_{k}: 40^{\circ} \mathrm{C}$ and $55^{\circ} \mathrm{C}$.

For the refrigerants with high glide values, evaporation and condensation temperatures are obtained as suggested in [29], Eq. (1) and (2) respectively.

$$
\begin{aligned}
T_{o} & =\frac{1}{3} T_{\text {Bubble }}+\frac{2}{3} T_{\text {Dew }} \\
T_{k} & =\frac{1}{2} T_{\text {Bubble }}+\frac{1}{2} T_{\text {Dew }}
\end{aligned}
$$

For following comparisons, target cooling capacity will be constant for all conditions. Moreover, to complete cycle simulation, following assumptions are taken:

- Subcooling degree (at the condenser outlet): $2^{\circ} \mathrm{C}$.

- Isenthalpic process is considered at the expansion valve.

- Ideal compression (the refrigerants selected are recently developed and there is no data available about compression performance).

- There is no heat transfer to the surroundings.

- Pressure drops are neglected.

- Heat exchange efficiency in subcooler $\left(\varepsilon_{S C}\right): 0.7$.

- Heat exchange efficiency in IHX $\left(\varepsilon_{I H X}\right): 0.3$ (in order to avoid high discharge temperatures).

The total superheating degree (between saturation temperature and compressor suction) and superheating degree at intermediate pressure (between saturated vapour and the high pressure compressor suction) for $\mathrm{R} 404 \mathrm{~A}$ is $7^{\circ} \mathrm{C}$, for the rest of refrigerants is corrected [29], Eq. (3) and (4):

$$
\begin{aligned}
& S H_{\text {Refrigerant with glide }, L P}=S H_{R 404 A}-\frac{1}{3} \text { Glide } \\
& S H_{\text {Refrigerant with glide }, I P}=S H_{R 404 A}-\frac{1}{2} \text { Glide }
\end{aligned}
$$

The thermodynamic states of refrigerants studied are based on data from REFPROP v. 8 [30].

In two-stage configurations the inter-stage pressure is calculated using Eq. (5), obtaining the same compression rate in both stages [31]. 


$$
P_{I P}=\sqrt{P_{L P} P_{H P}}
$$

The mass flow rate at low pressure stage, $\dot{m}_{L P}$, is calculated in Eq. (6).

$$
\dot{m}_{L P}=\frac{\dot{Q}_{o}}{\left(h_{o, o u t}-h_{o, \text { in }}\right)}
$$

The volumetric flow rate at suction, $\dot{V}_{\text {suc }}$, is obtained from mass flow rate and density, Eq. (7).

$$
\dot{V}_{s u c}=\frac{\dot{m}}{\rho_{\text {suc }}}
$$

For IHX configuration, Eq. (8) is used to simulate its performance.

$$
\varepsilon_{\text {IHX }}=\frac{T_{\text {suc }}-T_{o, \text { out }}}{T_{k, \text { out }}-T_{o, \text { out }}}
$$

To calculate mass flow rate at the high pressure stage in DI configuration, Eq. (9) is applied.

$$
\dot{m}_{H P}=\dot{m}_{L P} \frac{\left(h_{\text {disc }, L P}-h_{k, \text { out }}\right)}{\left(h_{s u c, H P}-h_{k, \text { out }}\right)}
$$

For SC Configuration $\dot{m}_{H P}$ is obtained from Eq. (10), using Eq. (11) to obtain the outlet enthalpy at the Intermediate Pressure stage.

$$
\begin{gathered}
\dot{m}_{H P}=\dot{m}_{L P} \frac{\left(h_{\text {disc }, L P}-h_{I P, \text { out }}\right)}{\left(h_{s u c, L P}-h_{I P, \text { out }}\right)} \\
h_{I P, \text { out }}=\frac{h_{k, \text { out }} h_{\text {disc }, L P}-h_{o, \text { in }} h_{\text {suc }, H P}}{\left(h_{k, \text { out }}+h_{\text {disc }, L P}\right)-\left(h_{o, \text { in }}+h_{\text {suc }, H P}\right)}
\end{gathered}
$$

The Coefficient of Performance, $C O P$, is calculated from the cooling capacity at the evaporator and the compressor power consumption $\left(\dot{W}_{C}\right)$, Eq. (12).

$$
C O P=\frac{\dot{Q}_{o}}{\dot{W}_{C}}
$$

$\dot{W}_{C}$ for one-stage configuration is expressed in Eq. (13) as a product of mass flow rate and the isentropic enthalpy increase at the compressor.

$$
\dot{W}_{C}=\dot{m}_{L P} \Delta h_{c}
$$

$\dot{W}_{C}$ for two-stage configurations Eq. (14) is applied, separating $\dot{W}_{C}$ value in the two compression stages. 


$$
\dot{W}_{C}=\dot{m}_{L P} \Delta h_{c, L P}+\dot{m}_{H P} \Delta h_{c, H P}
$$

\section{Results and discussion}

This section presents the main results of the energetic simulation carried out varying the evaporation temperature $\left(T_{o}\right)$ and the condensation temperature $\left(T_{k}\right)$ for the four configurations analysed. As exposed in section 2, refrigerants R407A, R407F, L40, DR7, N40 and DR-33 have been developed as low GWP retrofit alternatives for R404A.

COP (parameter commonly used to evaluate energy performance of system) and volumetric flow rate at compressor suction (it can show the adaptation of the refrigerant to existing compressor) are the parameters chosen in this study to determine the suitability of alternatives as retrofit replacements for R404A. Indeed, the results are shown as a relative difference $\left(\% \dot{V}_{s u c}\right.$ and $\left.\% C O P\right)$ of each configuration working with alternative fluids taking as reference the same configuration working with R404A, as shown in Eq. (15) and (16).

$$
\begin{aligned}
& \% \dot{V}_{\text {suc }}=\left(\frac{\dot{V}_{\text {suc alternative fluid }}-\dot{V}_{\text {Suc }_{R 404 A}}}{\dot{V}_{\text {Suc }} \text { R } 404 A}\right) \cdot 100 \\
& \% C O P=\left(\frac{\text { COP }_{\text {alternative fluid }}-\operatorname{COP}_{R 404 A}}{\operatorname{COP}_{R 404 A}}\right) \cdot 100
\end{aligned}
$$

Furthermore, numerical results are shown in Table 2, Table 3 and Table 4.

Table 2. $\% \dot{V}_{\text {suc }, L P}$ Theoretical results.

Table 3. $\% \dot{V}_{s u c, H P}$ Theoretical results.

Table 4. \%COP Theoretical results.

\subsection{Volumetric flow rate at low-pressure compressor suction}

Fig. 2 presents the results for $\% \dot{V}_{s u c, L P}$ at two evaporation temperatures, two condensation temperatures, four different configurations and six refrigerants. Depending on the conditions and the configuration studied, the results vary widely. While the lowest differences take place at higher condensation temperatures, the highest $\dot{V}_{S u c, L P}$ relative differences result with DR-7 at low condensation temperatures and with DR-33 at high condensation temperatures. The refrigerant with the lowest $\dot{V}_{s u c, L P}$ values is $\mathrm{R} 407 \mathrm{~F}$ for all conditions.

Fig. 2. a) shows $\% \dot{V}_{s u c, L P}$ for Basic Cycle and Direct Injection configurations. As $\dot{V}_{s u c, L P}$ depends on suction density and low pressure mass-flow rate, the same results are obtained with Basic Cycle configuration and Direct Injection configuration at the low pressure compressor inlet. Except for R407F, the $\dot{V}_{s u c, L P}$ relative difference values are positive (greater than R404A) at low condensation temperatures. 
Fig. 2.a) $\% \dot{V}_{\text {suc }}$ results for BC.

In Fig. 2. b) is represented $\dot{V}_{s u c, L P}$ relative differences for Basic Cycle with Internal Heat Exchanger configuration. $\dot{V}_{s u c, L P}$ values of R404A are reduced by the use of the IHX more than those of alternative fluids. In this way, $\dot{V}_{S u c, L P}$ relative differences, compared to $\mathrm{BC}$ and $\mathrm{DI}$ configurations, are incremented for all refrigerants. The lowest values are obtained for $\mathrm{R} 407 \mathrm{~F}$ at $T_{o}=-10^{\circ} \mathrm{C}$ and $T_{k}=55^{\circ} \mathrm{C}$ instead of $T_{o}=-40^{\circ} \mathrm{C}$ and $T_{k}=55^{\circ} \mathrm{C}$, as happens for BC. DR-7 and DR-33 have the highest $\dot{V}_{s u c, L P}$ relative differences. The following refrigerants are L40, R407A and N40. The refrigerant with the lowest values is R407F.

Fig. 2.b) $\% \dot{V}_{\text {suc }}$ results for BCIHX.

The evolution of $\dot{V}_{s u c, L P}$ relative differences for SC is different from the other configurations, Fig. 2.c). The influence of the condensation temperature is stronger than the evaporation temperature. The $\dot{V}_{s u c, L P}$ relative differences obtained at $T_{o}=-40^{\circ} \mathrm{C}$, $T_{k}=55^{\circ} \mathrm{C}$ are higher than those obtained at $T_{o}=-10^{\circ} \mathrm{C}, T_{k}=40^{\circ} \mathrm{C}$. Besides, the results are in general higher than the other configurations studied, due to the major increase of mass flow rate for replacements promoted by the subcooler. Refrigerant with the highest $\dot{V}_{\text {suc,LP }}$ relative differences is DR-7, followed by L40.

Fig. 2.c) $\% \dot{V}_{\text {suc }}$ results for SC.

\subsection{Volumetric flow rate at high pressure compressor suction}

In Fig. 3 are shown the $\dot{V}_{s u c, H P}$ relative differences compared with R404A. The highest relative differences are obtained with DR-7 in all conditions and configurations, and the lowest with R407F.

For DI configuration, Fig. 3a), all results are negative except DR-7 at $T_{o}=-40^{\circ} \mathrm{C}$, $T_{k}=55^{\circ} \mathrm{C}$. The minimum $\dot{V}_{s u c, H P}$ values for alternatives results at higher evaporation temperatures, then with lower condensation temperatures. As said before, the refrigerant with the highest $\dot{V}_{s u c, H P}$ values is R407F, followed by DR-33 and then by N40 and R407A. The $\dot{V}_{s u c, H P}$ relative difference of R407A depends greatly of the conditions considered.

Fig. 3.a) $\% \dot{V}_{s u c, H P}$ results compared with R404A for DI. 
For SC configuration, Fig. 3b), contrary to what happens in DI most of the $\dot{V}_{s u c, H P}$ relative values are positive. Similarly to $\dot{V}_{s u c, H P}$ case, the major differences are obtained at $T_{o}=-40^{\circ} \mathrm{C}$ and $T_{k}=40^{\circ} \mathrm{C}$ following the same trend in the results.

Fig. 3.b) $\% \dot{V}_{\text {suc }, H P}$ results compared with R404A for SC.

\subsection{Coefficient of Performance}

In Fig. $4 \% C O P$ are shown for the configurations proposed. All differences obtained are positive, so it can be seen that all refrigerants perform better than R404A. Best results are obtained with flammable long-term alternatives, then non-flammable long-term alternatives and finally mid-term refrigerants. Larger differences between replacements and $\mathrm{R} 404 \mathrm{~A}$ are obtained at higher compression ratios; this is when higher condensation temperature and lower evaporation temperature are considered.

As shown in Fig. 4.a), higher $\%$ COP values are obtained when Basic Cycle configuration is considered. L40 have higher COP relative differences at lower compression ratio and DR-7 at higher compression ratio. Next refrigerants in performance are the non-flammable at long-term, having similar results with a slight advantage for DR-33. Finally, commercially available refrigerants have lower results, but $\mathrm{R} 407 \mathrm{~F}$ is a good alternative in almost in all the cases.

Fig. 4.a) \%COP results for $\mathrm{BC}$.

Fig. 4.b) shows $\% C O P$ for a Basic cycle with Internal Heat Exchanger configuration $\left(\varepsilon_{I H X}=0.3\right)$. On the whole, results are closer to R404A than those obtained without IHX, so it can be deduced that IHX produces more benefices on R404A COP than on its alternatives. Refrigerant with the highest $C O P$ is DR-7. In BC configuration, contrary to BCIHX case, L40 \%COP presents higher than DR-7 in some conditions. Nonflammable long term refrigerants, DR-33 and N40, are affected in the same proportion. Refrigerants with the lowest values of \%COP are R407F and R407A.

Fig. 4.b) \%COP results for BCIHX.

Fig. 4.c), represents $C O P$ evaluation for Direct Injection configuration. Results are very similar to those obtained for Basic cycle. The highest differences results with L40 and DR-7. The other refrigerants (the non-flammable alternatives) ranked by COP relative differences are DR-33, N40, R407F and R407A.

Fig. 4.c) $\% C O P$ results for DI. 
The results of last case studied, Subcooler Cycle, are presented in Fig. 4.d). As occurs in the other configurations, flammable refrigerants have the highest $\% C O P$ values. Next refrigerants in terms of energy performance are the non-flammable options, DR-33 and N40. The last refrigerants are the mid-term replacements, R407F and R407A. As is the case in $\mathrm{BC}$ configuration, $\mathrm{L} 40$ and $\mathrm{R} 407 \mathrm{~F}$ are the refrigerants in which the heat exchange (IHX or subcooler) causes a minor influence on the COP results.

Fig. 4.d) \%COP results for SC.

Finally, Fig. 5 shows a comparison between COP obtained with a Basic Cycle and the other configurations selected, Eq. 17. COP values obtained with BCIHX and SC are greater with R407A, DR-7 and DR-33 whereas with the DI configuration the results are lower, especially considering the same refrigerants. For the SC configuration the lowest values results using R407F, DR-7 and DR-33. For the rest of alternatives; R407A, L40 and N40; the difference is hardly noticeable in BCIHX and DI configurations, being slightly higher in SC.

$$
\% C O P=\left(\frac{C O P_{\text {configurations }}-C O P_{B C}}{C O P_{B C}}\right) \cdot 100
$$

Fig. 5. \%COP results compared with Basic Cycle.

\section{Conclusions}

In this paper a comparative study in terms of energy performance of different vapour compression configurations using R407A, R407F, L40, DR-7, N40 and DR-33 as working fluids has been carried out, taking R404A as reference. The replacements selected have good environmental properties and similar operating conditions as R404A, although they have considerable values of glide. To avoid high discharge temperatures, two-stage configurations are considered. The main conclusions of this work are the following:

Depending on the configuration, the low pressure suction volumetric flow rate comparison study has significant variations. So, for BC (or DI) and BCIHX the values are higher for replacements at low condensation pressures but lower at high pressures. For SC the volumetric flow rate resulting is higher for replacements than the baseline in all conditions, with the exception of R407F that has lower values at high evaporation temperatures. The highest values are obtained with DR-7, L40 and DR-33 in accordance with the case selected. R407A and N40 present greater values than R404A but lower results than the other alternative refrigerants. Considering the high pressure suction volumetric flow rate, for DI configuration nearly all R404A results are higher than those obtained with the alternatives. For SC negative differences are obtained only with R407F; and R407A and N40 in some conditions. As results are so diverse, in order to study the compressor viability in substitution, the working conditions and final configuration should be narrowed. 
Better energy efficiency is obtained with all replacements compared to R404A under all conditions studied. The greatest difference between R404A and the replacements is shown when high compression ratio and BC and DI configurations are considered. The most efficient refrigerants are the low flammable and very low GWP long-term alternatives L40 and DR-7. In those applications where mildly-flammable refrigerants are not allowed, the best options in terms of energy performance are DR-33 and N40. Finally, the lowest COP increments are obtained with R407F and then with R407A, even though those are still promising values. Those refrigerants have the advantage that they are commercially available and their discharge temperatures are the lowest among all replacement refrigerants.

\section{Acknowledgements}

The authors thankfully acknowledge "Ministerio de Educación, Cultura y Deporte" for supporting this work through "Becas y Contratos de Formación de Profesorado Universitario del Programa Nacional de Formación de Recursos Humanos de Investigación del ejercicio 2012" The authors also want to acknowledge Honeywell International Inc. for supporting this work.

\section{References}

[1] UNEP. Decisions adopted by the nineteenth meeting of the parties to the Montreal Protocol on substances that deplete the ozone layer. Nairobi, Kenya: United Nations Environment Programme (UNEP) Ozone Secretariat; 2007.

[2] J.M. Calm. The next generation of refrigerants - Historical review, considerations, and outlook. International Journal of Refrigeration 31 (2008), 1123-1133.

[3] Kyoto Protocol, Report of the Conference of the Parties, United Nations Framework Convention on Climate Change (UNFCCC), 1997.

[4] Directive 2006/40/EC of The European Parliament and of the Council of 17 May 2006 relating to emissions from air conditioning systems in motor vehicles and amending Council Directive 70/156/EC. Official Journal of the European Union.

[5] Ley 16/2013, de 29 de octubre, por la que se establecen determinadas medidas en materia de fiscalidad medioambiental y se adoptan otras medidas tributarias y financieras. Boletín Oficial del Estado.

[6] D. Cowan, J. Gartshore, I. Chaer, C. Francis, G. Maidment. REAL Zero Reducing refrigerant emissions \& leakage - feedback from the IOR Project. Institute of Refrigeration, 22 April 2010.

[7] U.S. Environmental Protection Agency. Transitioning to Low GWP Alternatives in Commercial Refrigeration, 2010. Retrieved online at: http://www.epa.gov/ozone/downloads/EPA_HFC_ComRef.pdf ， 3 September 2013.

[8] M. Mohanraj, S. Jayaraj, C. Muraleedharan. Environment friendly alternatives to halogenated refrigerants-A review. International Journal of Greenhouse gas control 3 (2009), 108-119. 
[9] Z. Yang, X. Wu. Retrofits and options for the alternatives to HCFC-22. Energy 59 (2013), 1-21.

[10] M. W. Spatz, S. F. Yana Motta. An evaluation of options for replacing HCFC22 in medium temperature refrigeration systems. International Journal of Refrigeration 27 (2004), 475-483.

[11] R. Llopis, E. Torrella, R. Cabello, D. Sánchez. Performance evaluation of R404A and R507A refrigerant mixtures in an experimental double-stage vapour compression plant. Applied Energy 87 (2010) 1546-1553.

[12] Y.T. Ge, R. Cropper. Performance simulation of refrigerated display cabinets operating with refrigerants R22 and R404A. Applied Energy 85 (2008), 694707.

[13] A. Arora, S.C. Kaushik. Theoretical analysis of a vapour compression refrigeration system with R502, R404A and R507A. International Journal of Refrigeration 31 (2008), 998-1005.

[14] Y. Ge, R. Cropper. Air-cooled condensers in retail systems using R22 and R404A refrigerants. Applied Energy 78 (2004), 95-110.

[15] IPPC, Climate change 2001-the scientific basis, intergovernmental panel on climate change. Cambridge: Cambridge University Press, 2001.

[16] H. Jürgensen. Refrigerants in Future and in Legislation 2013. In Stockholm, Sweden, 10 April 2013.

[17] Linde Gases Division. R407A. Lower Global Warming Potential replacement for R404A. Retrieved online at: http://www.lindegas.com/internet.global.lindegas.global/en/images/BAMPG_Refrigerants_407A fin17_92206.pdf, 5 September 2013.

[18] Linde Gases Division. R407F - Genetron ${ }^{\circledR}$ Performax $^{\mathrm{TM}}$ LT. Lower Global Warming Potential replacement for R404A. Retrieved online at: http://www.linde-

gas.com/internet.global.lindegas.global/en/images/BAMPG_Refrigerants_407F_ fin17_92205.pdf, 5 September 2013.

[19] Honeywell International Inc. Honeywell Solstice ${ }^{T M}$ N40 Refrigerant Improved Energy Efficiency Case Study, Gaining Competitive Advantage through Improved Energy Efficiency and Reduced Environmental Impact - September 2012. Retrieved online at: http://www.honeywellrefrigerants.com/india/resources/customer-case-studies/honeywell-solstice-n40improved-energy-efficiency-case-studyl, 3 September 2013.

[20] B.H. Minor, F. Rinne. Low GWP R-404A Alternatives for Commercial Refrigeration. ASHRAE Transactions 118(1), Chicago, IL, 9-11 October 2012.

[21] American Society of Heating, Refrigerating and Air-Conditioning Engineers. ASHRAE, Standard 34 Designation and Safety Classification of Refrigerants, 2010.

[22] S. F. Yana Motta, E. V. Becerra, M. W. Spatz. Low Global Warming Refrigerants For Commercial Refrigeration Systems. In: International Refrigeration and Air Conditioning Conference, 2012. Paper 1351.

[23] N.Q. Minh, N.J Hewitt, P.C. Eames. Improved Vapour Compression Refrigeration Cycles: Literature Review and Their Application to Heat Pumps. 
In: International Refrigeration and Air Conditioning Conference, 2006. Paper 795.

[24] P.A. Domanski, D.A. Didion, J.P. Doyle. Evaluation of Suction-line/Liquid-line Heat Exchange in the Refrigeration cycle. International Journal of Refrigeration 17 (1994), 487-493.

[25] K. Sumeru, H. Nasution, F.N. Ani, A review on two-phase ejector as an expansion device in vapor compression refrigeration cycle, Renewable and Sustainable Energy Reviews 16 (2012), 4927 - 4937.

[26] A. Subiantoro, K.T. Ooi, Economic analysis of the application of expanders in medium scale air-conditioners with conventional refrigerants, R1234yf and CO2, International Journal of Refrigeration 36 (2013), 1472 - 1482.

[27] E. Torrella, J.A. Larumbe, R. Cabello, R. Llopis, D. Sanchez. A general methodology for energy comparison of intermediate configurations in two-stage vapour compression refrigeration systems. Energy 36 (2012), 4119-4124.

[28] F. Memet, D.E. Mitu. First Law Analysis of a Two-stage Ejector-vapor Compression Refrigeration Cycle working with R404A. Analele Universitatii "Eftimie Murgu" Resita 18 (2011), 151-156.

[29] Honeywell. Technology issues regarding Blends of Refrigerants 2012. Retrieved online at: http://www.honeywellrefrigerants.com/europe/?document=honeywell-blends-technology-issues-2012presentation\&download=1, 1 October 2013.

[30] E.W. Lemmon, M.L. Huber, M.O. McLinden, REFPROP, NIST Standard Reference Database 23, v.8, National Institute of Standards, Gaithersburg, MD, USA, 2007.

[31] K. Baumann, E. Blass. Beitrag zur Ermittlung des Optimalen Mitteldruckes bei zweistufigen Kaltdampf Verdichter-Kältemaschinen. Kältetechnik, 1961, vol. 13 p. $210-216$. 


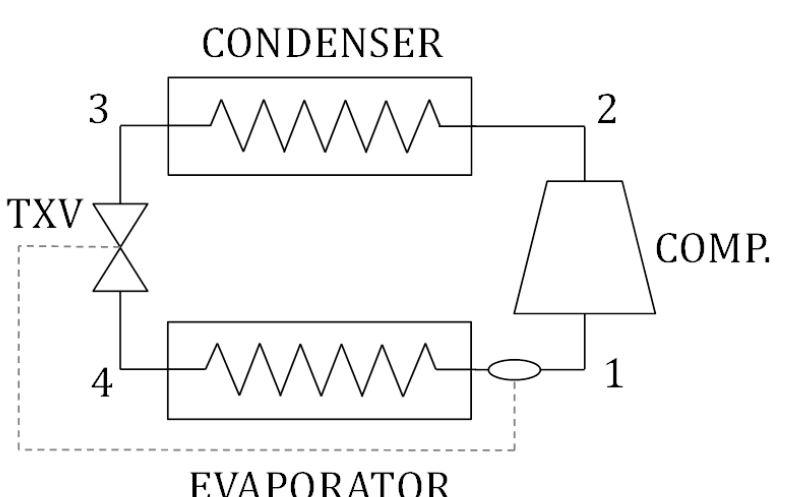

EVAPORATOR

a)
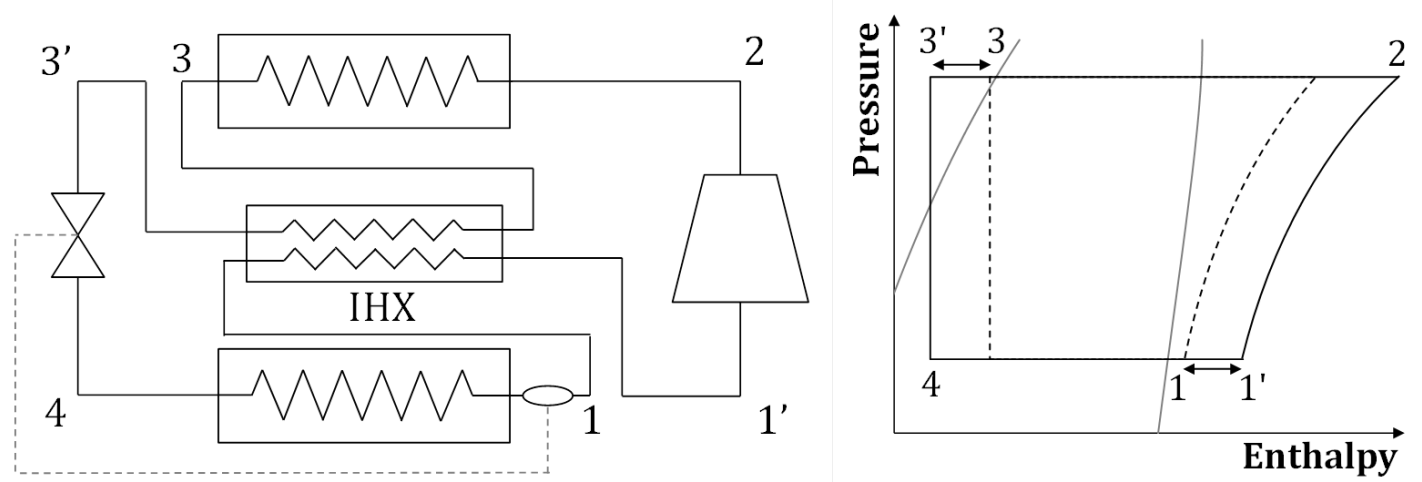

b)
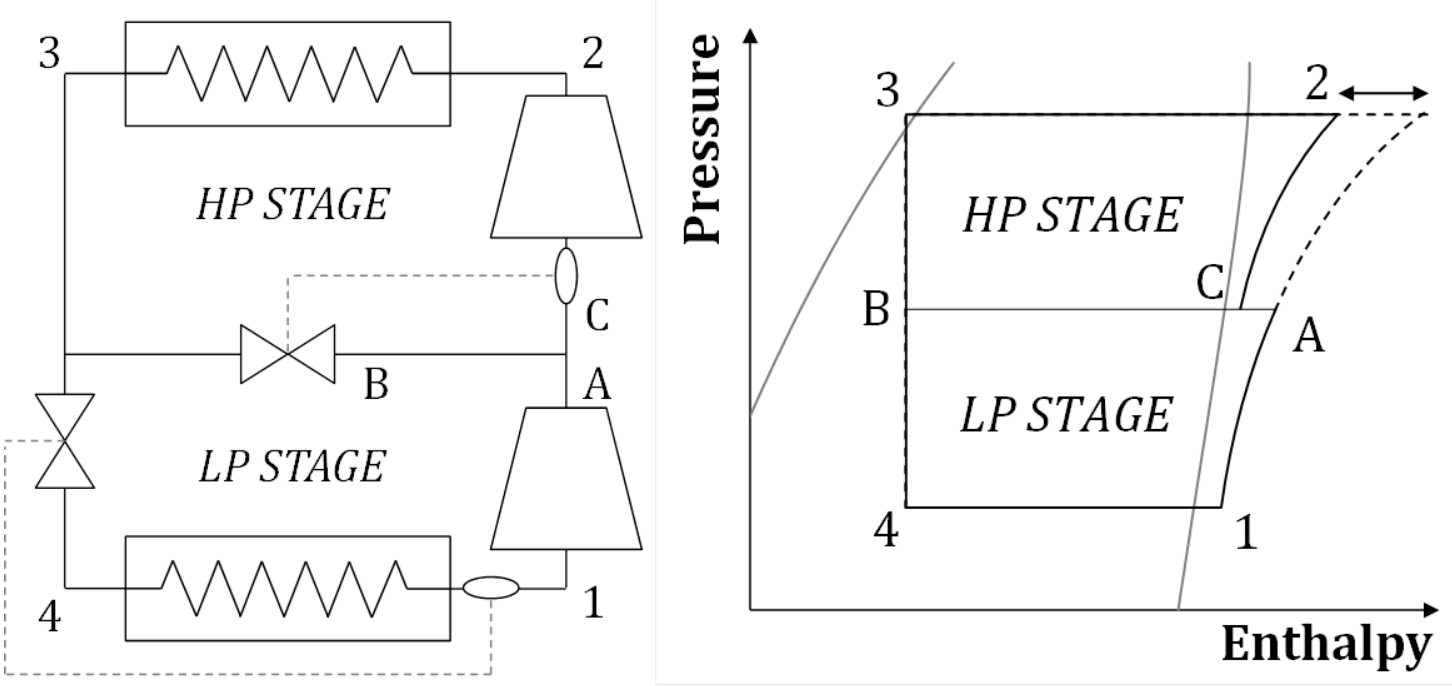

c) 

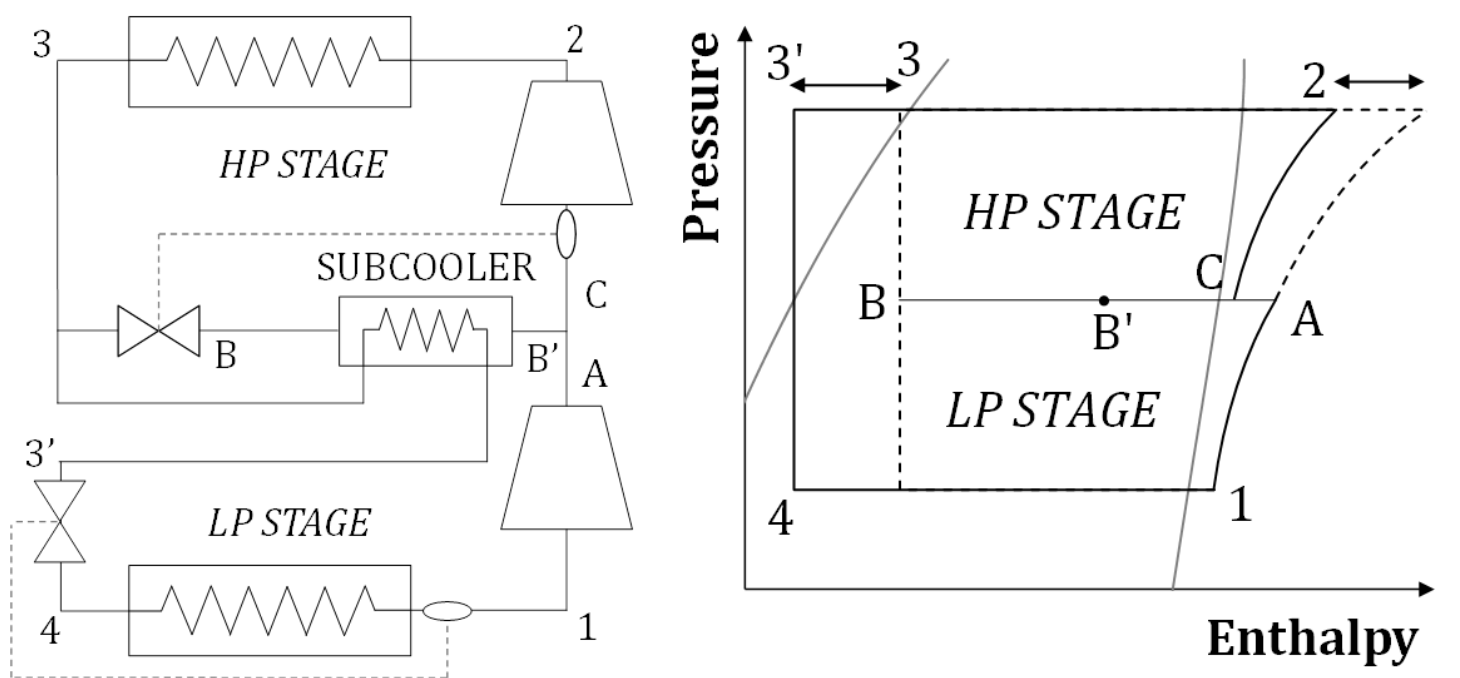

d)

Fig. 1. Diagram and P-h cycle of configurations a) Basic Cycle, b) Basic Cycle with IHX, c) Direct Injection, d) Subcooler Cycle. 


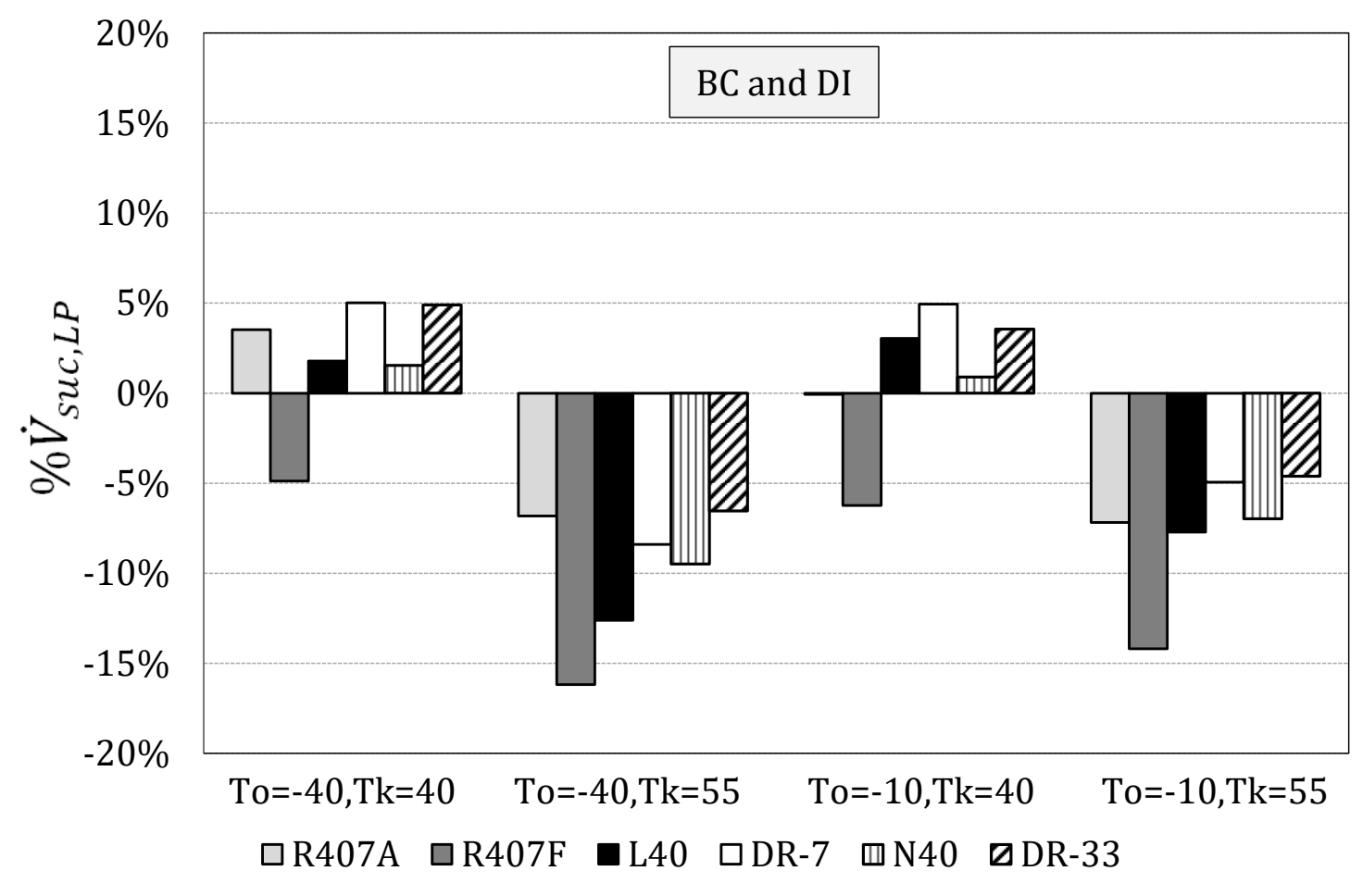

a)

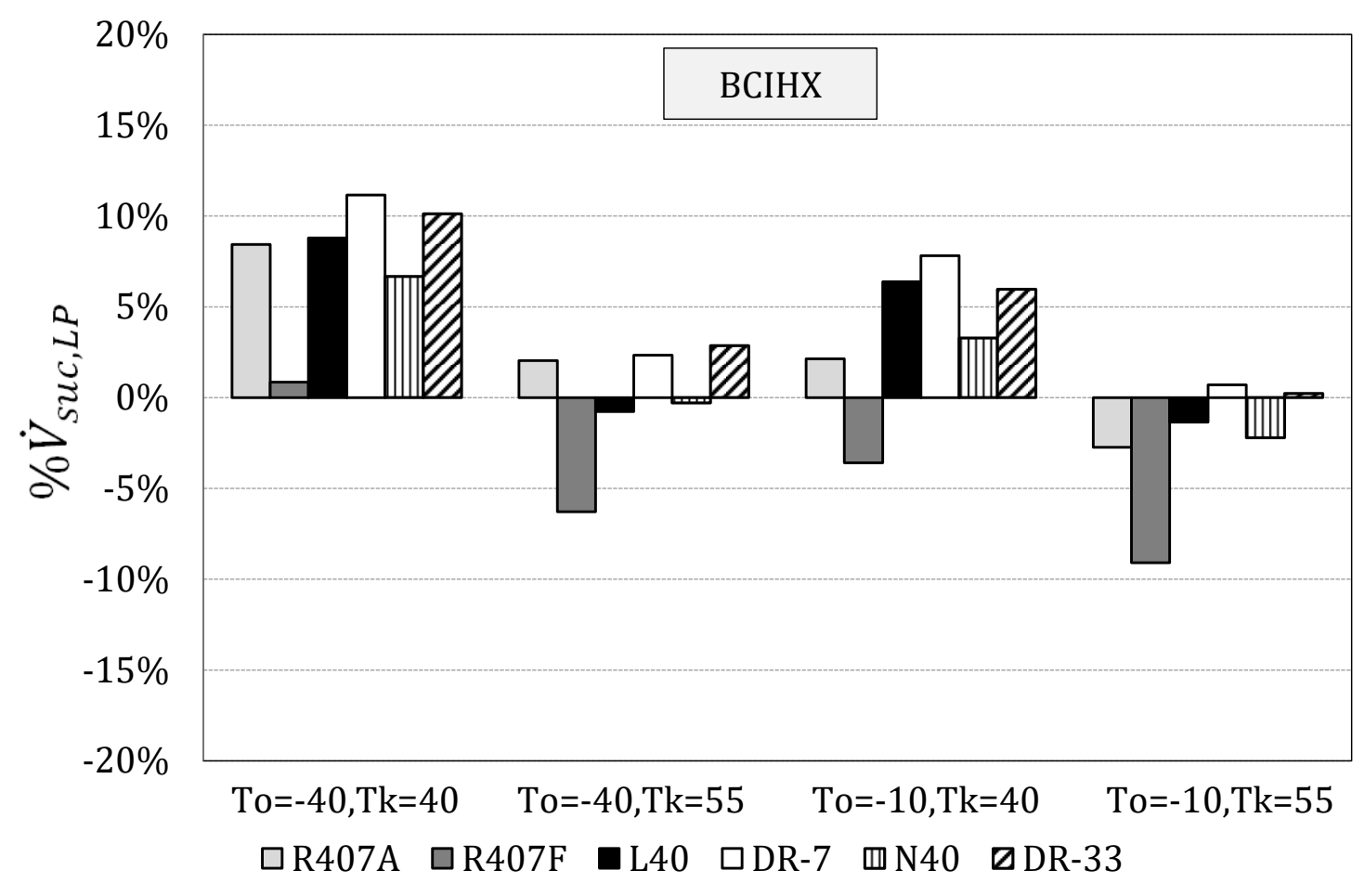

b) 


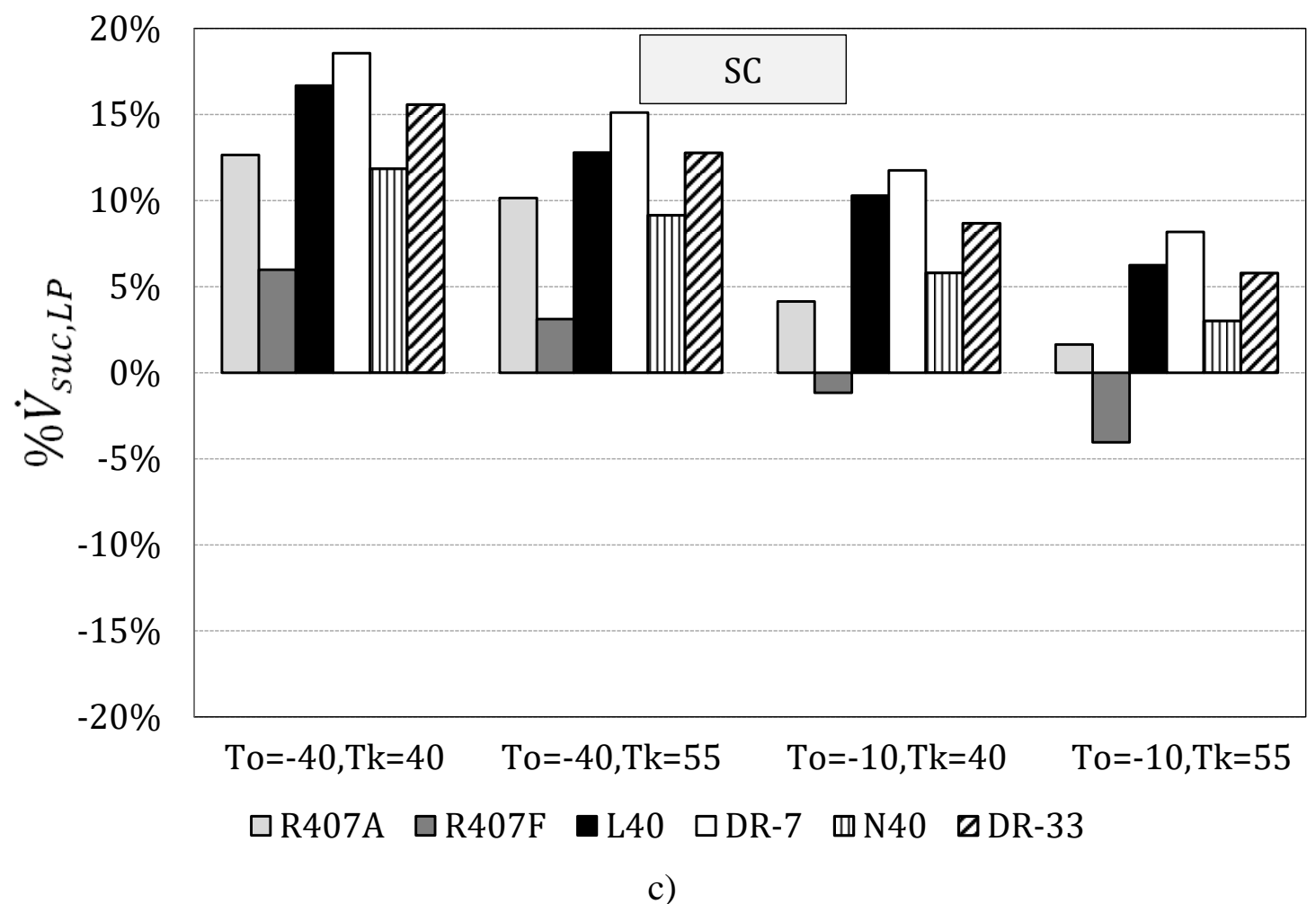

Fig. 2. $\% \dot{V}_{s u c, L P}$ results compared with R404A a) for BC and DI, b) for BCIHX, c) for SC. 


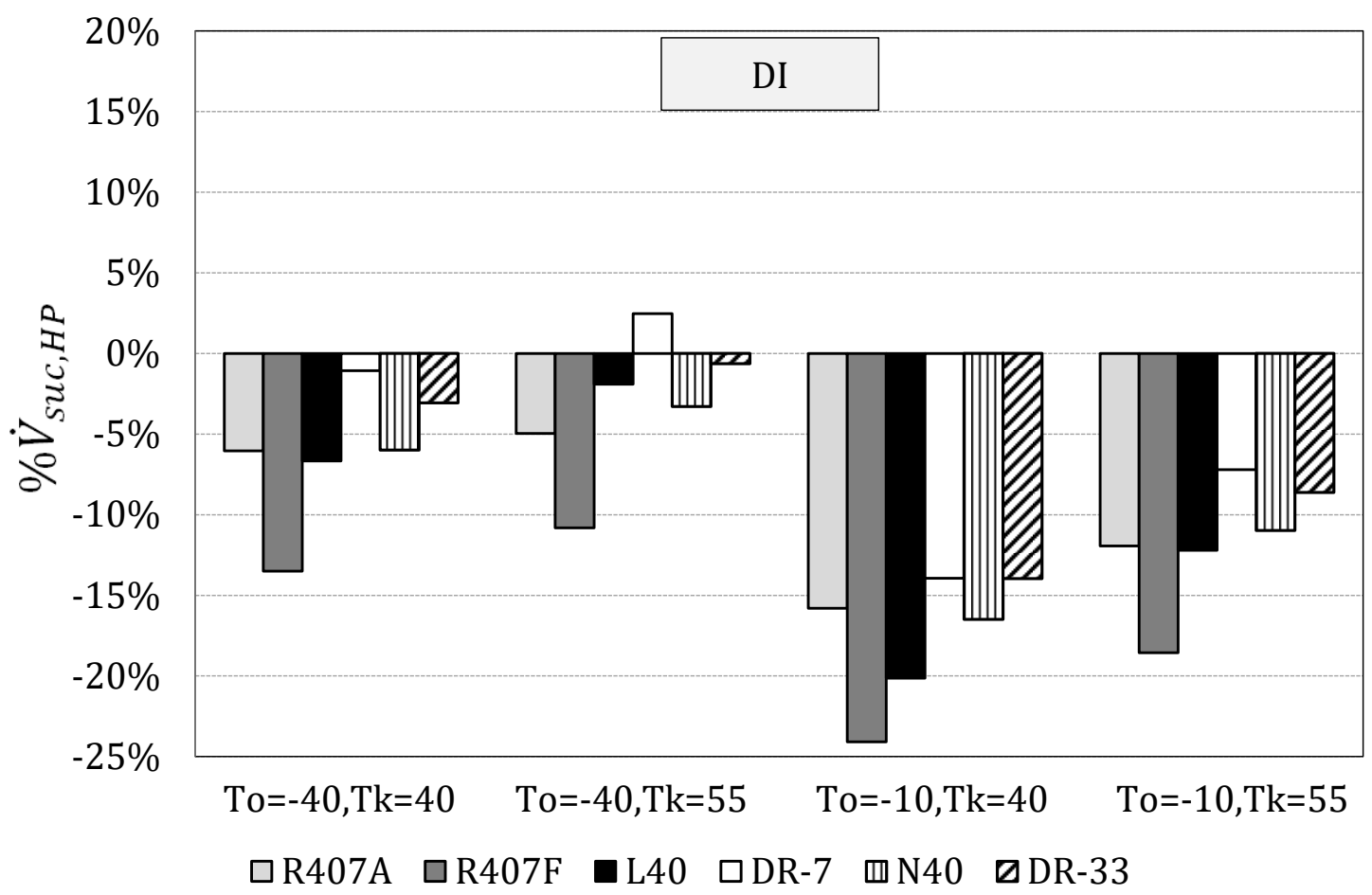

a)

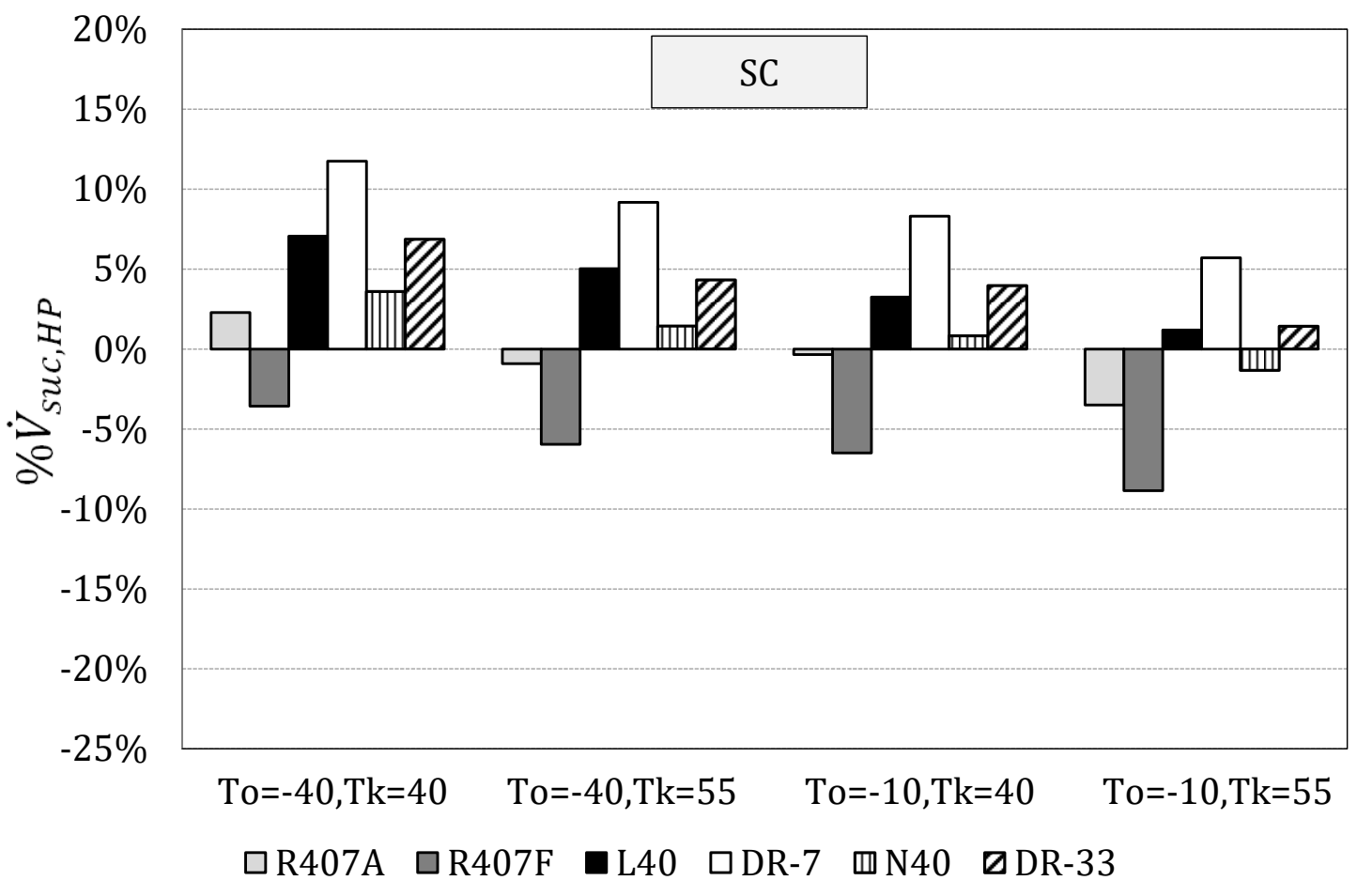

b)

Fig. 3. $\% \dot{V}_{s u c, H P}$ results compared with R404A a) for DI, b) for SC. 


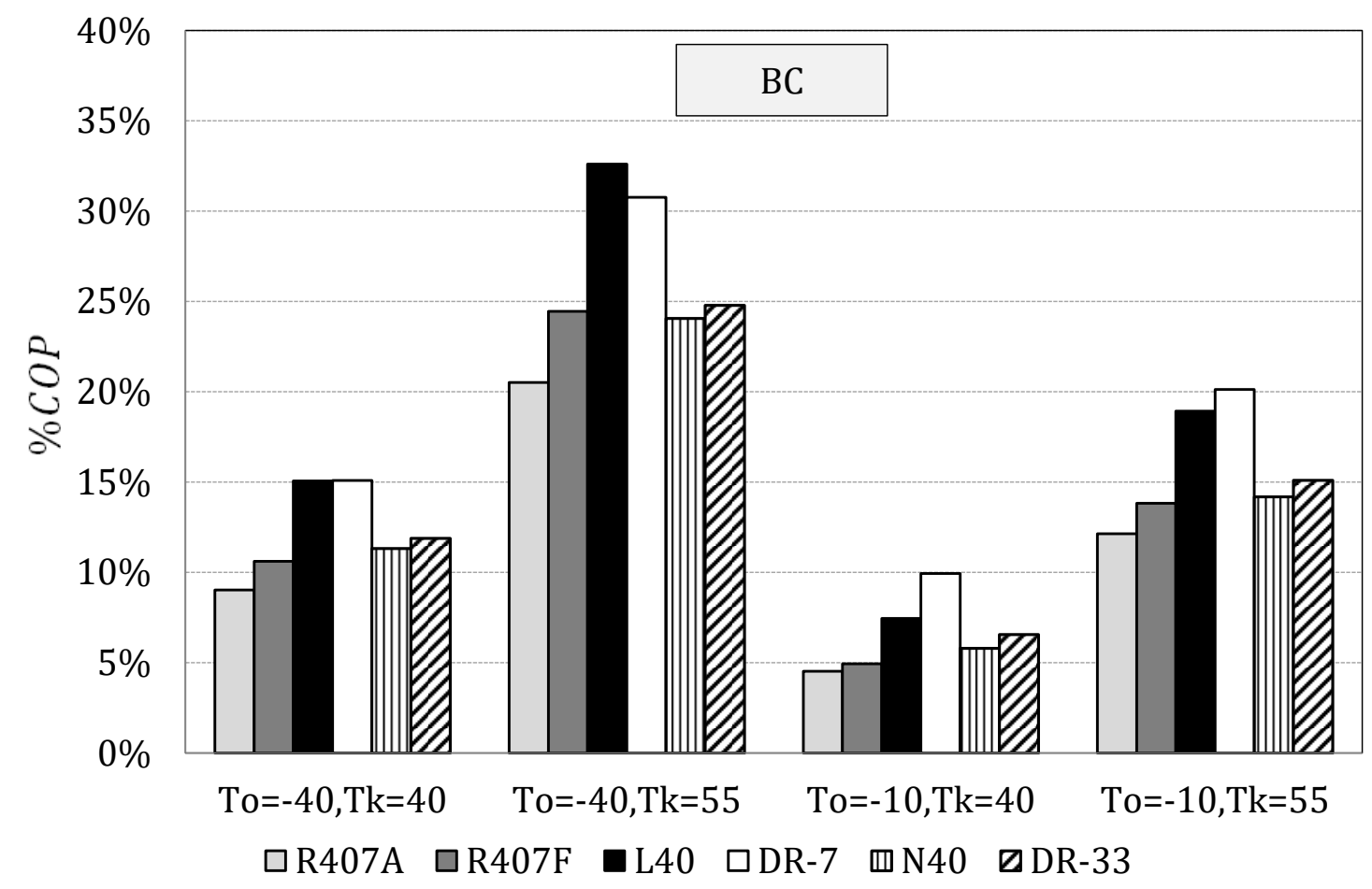

a)

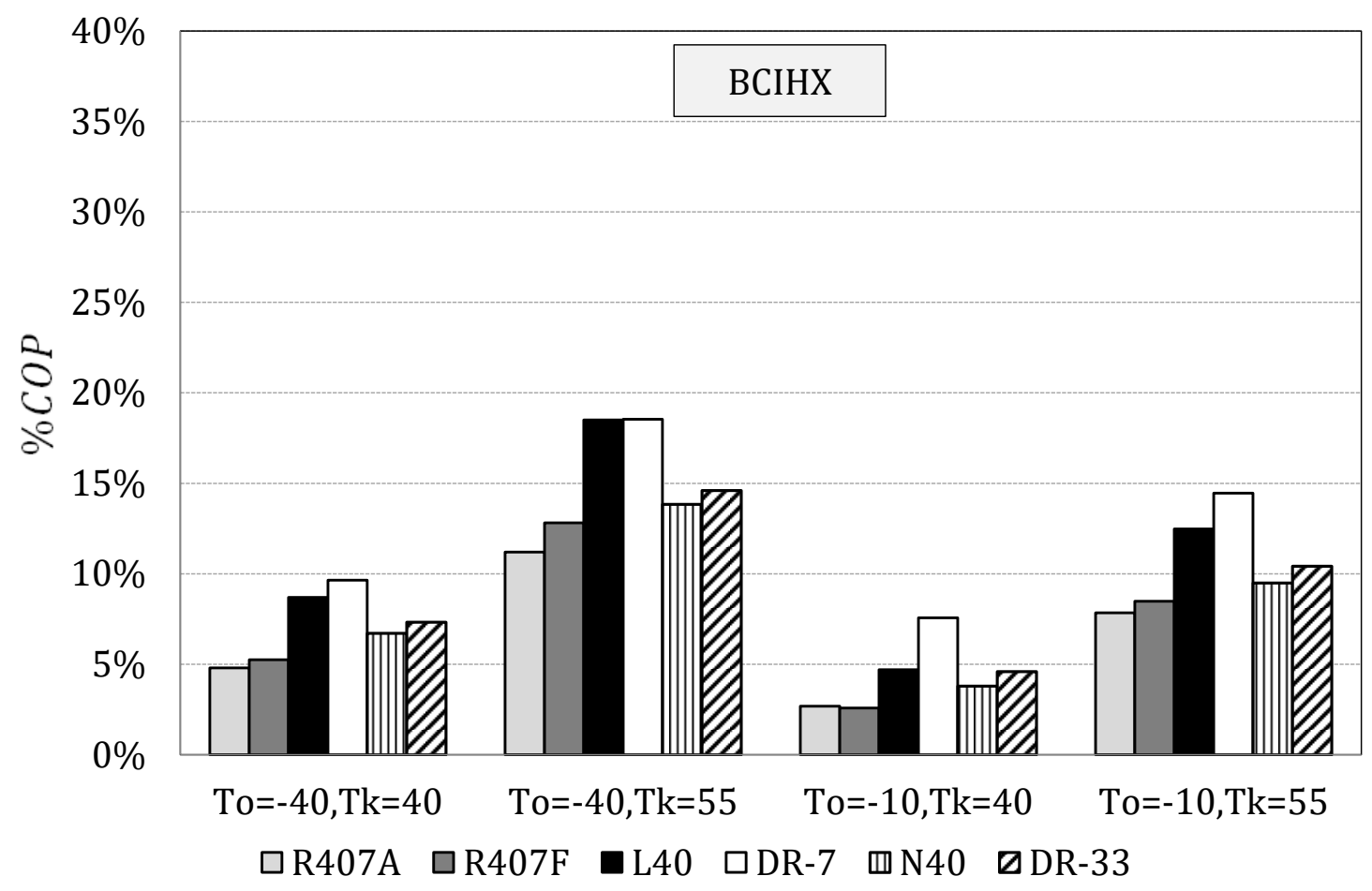

b) 


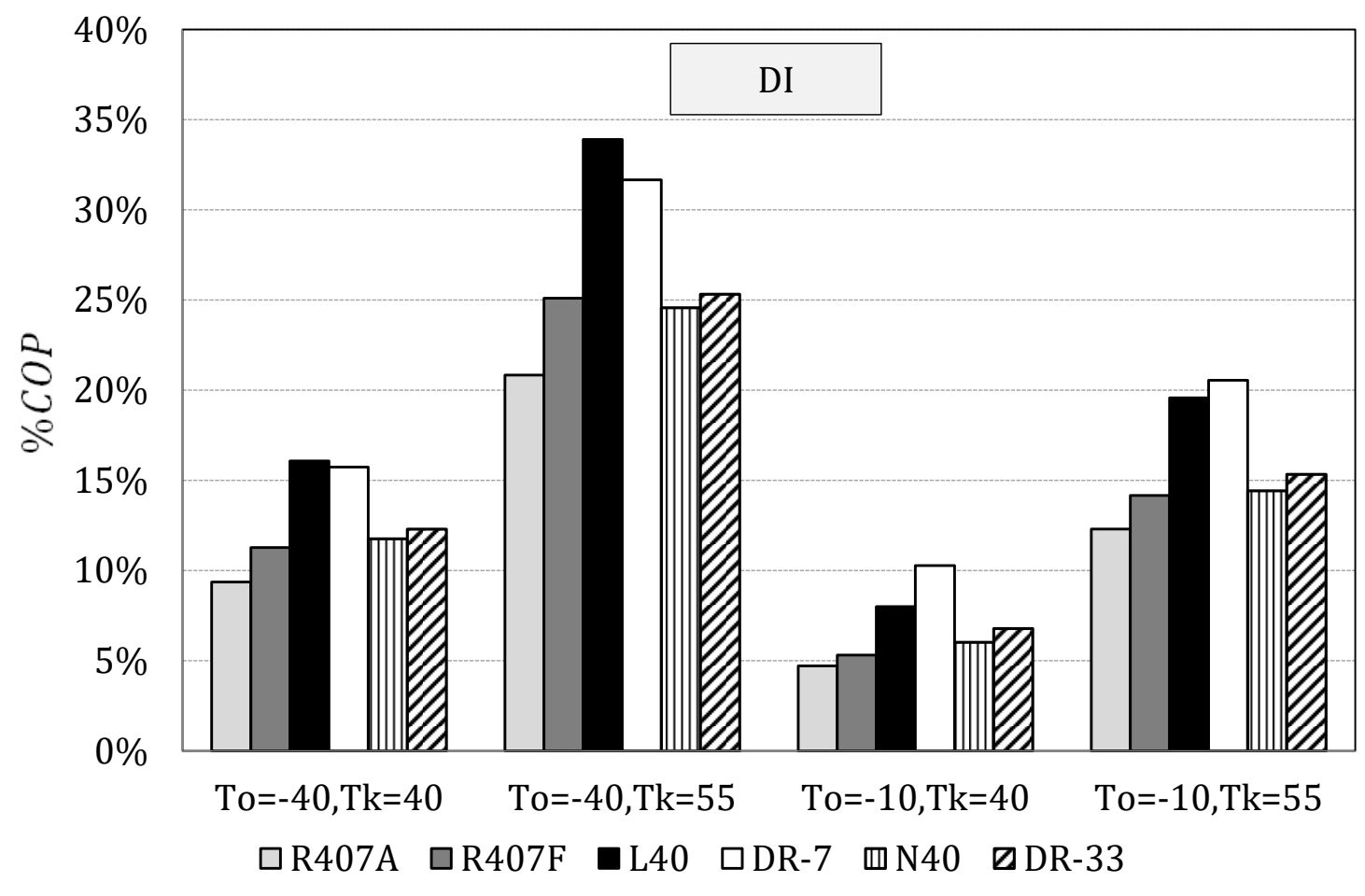

c)

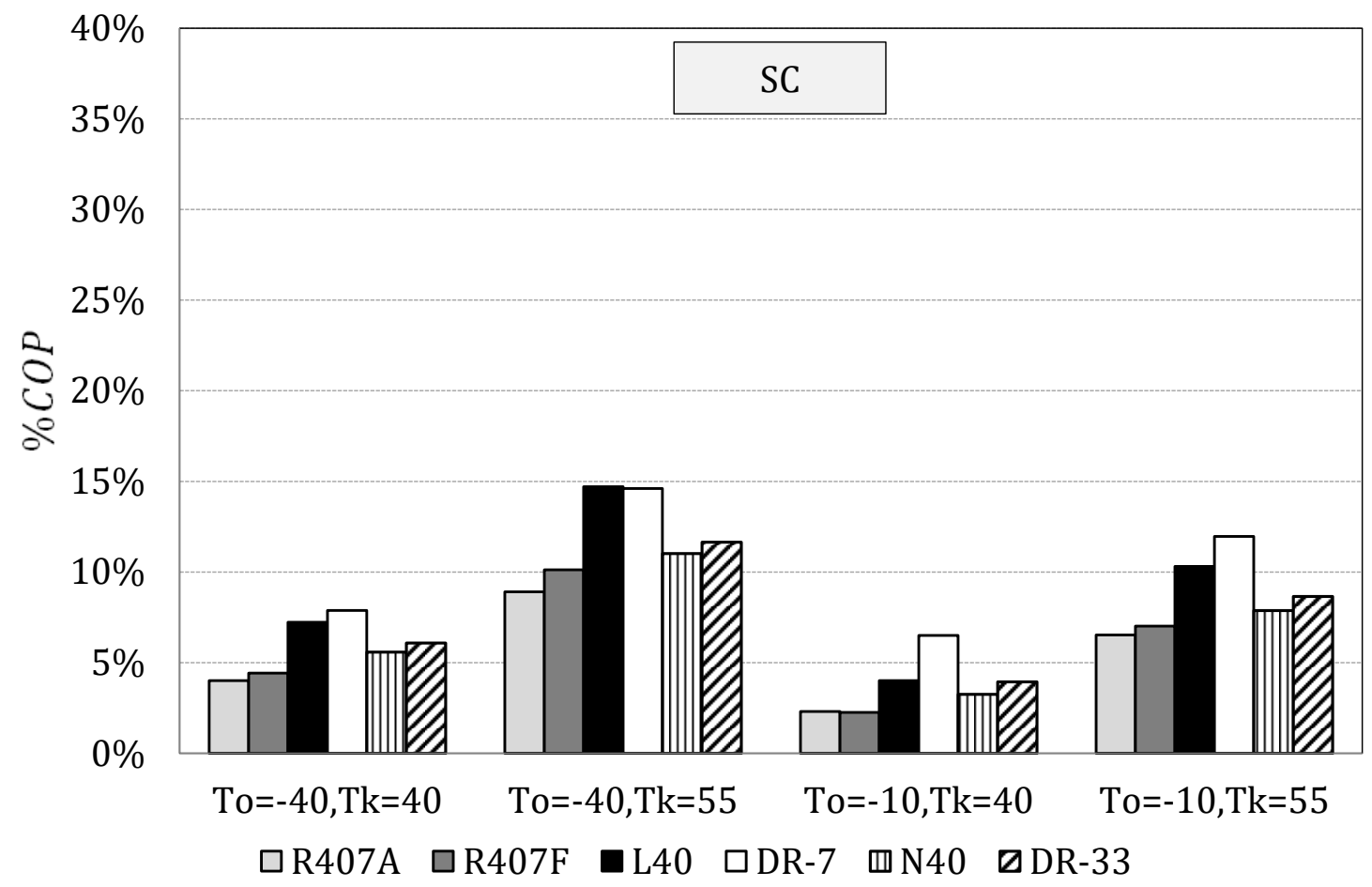

d)

Fig. 4. \%COP results compared with R404A a) for $\mathrm{BC}$, b) for BCIHX, c) for DI, d) for $\mathrm{SC}$. 


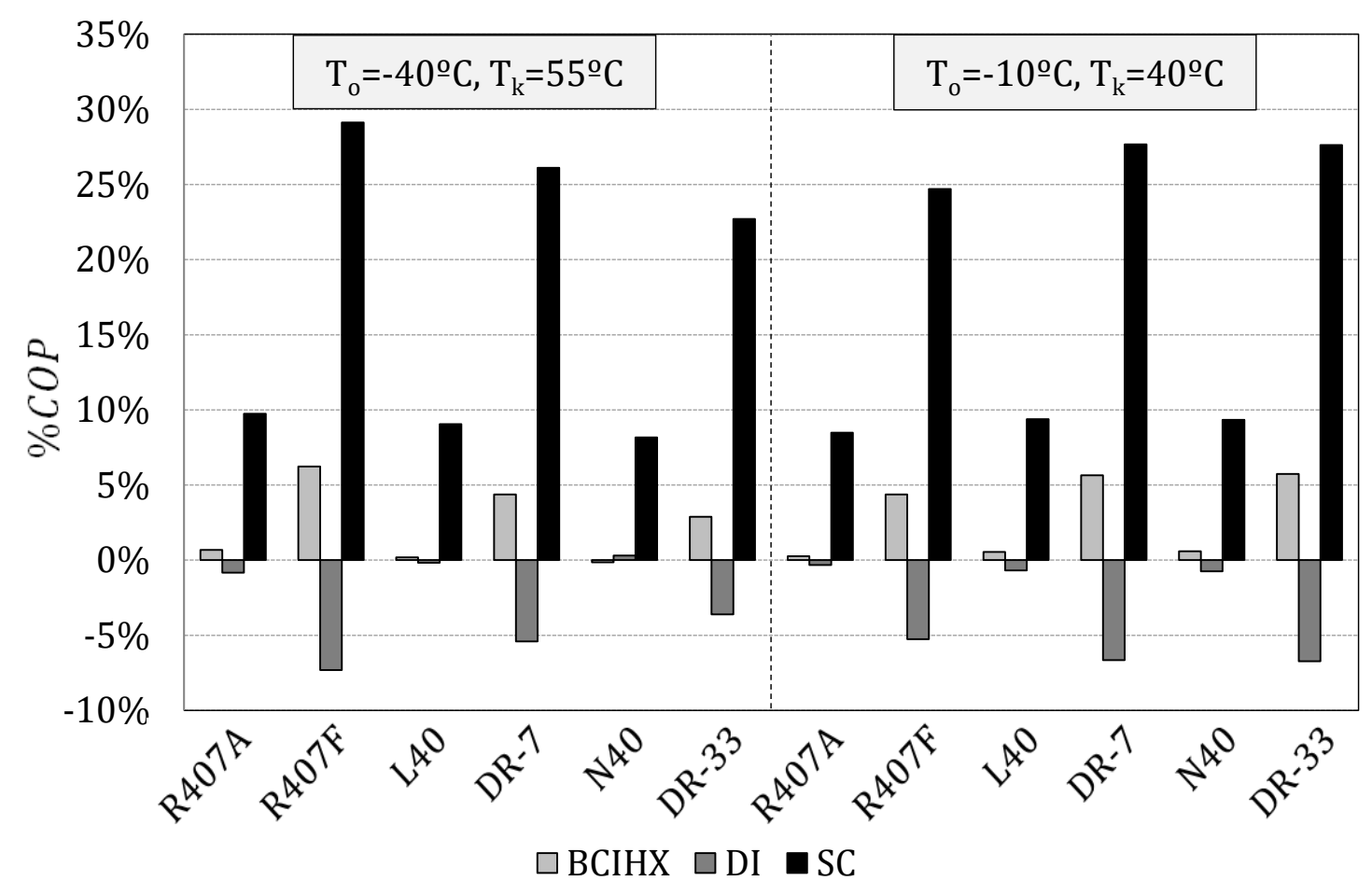

Fig. 5. \% COP results compared with Basic Cycle. 


\section{Figure Captions}

Fig. 1. Diagram and P-h cycle of configurations a) Basic Cycle, b) Basic Cycle with IHX, c) Direct Injection, d) Subcooler Cycle.

Fig. 2. $\% \dot{V}_{s u c, L P}$ results compared with R404A a) for BC and DI, b) for BCIHX, c) for SC.

Fig. 3. \% $\dot{V}_{\text {suc }, H P}$ results compared with R404A a) for DI, b) for SC.

Fig. 4. \%COP results compared with R404A a) for BC, b) for BCIHX, c) for DI, d) for SC.

Fig. 5. \%COP results compared with Basic Cycle. 
Table 1. Characteristics of refrigerants selected [17-20].

\begin{tabular}{lccccccc}
\hline & $\begin{array}{c}\text { ASHRAE } \\
\text { safety class. }\end{array}$ & $\begin{array}{c}\text { Boiling } \\
\text { Point }^{\mathrm{b}}\end{array}$ & Critical T & Critical P & Glide $^{\mathrm{b}}$ & ODP & $\begin{array}{c}\text { 100-yr } \\
\text { GWP }\end{array}$ \\
\hline R404A & $\mathrm{A} 1$ & $-46.5^{\circ} \mathrm{C}$ & $72{ }^{\circ} \mathrm{C}$ & $37.3 \mathrm{bar}$ & $0.8^{\circ} \mathrm{C}$ & 0 & 3922 \\
R407A & $\mathrm{A} 1$ & $-45.3^{\circ} \mathrm{C}$ & $82.3^{\circ} \mathrm{C}$ & $45 . \mathrm{bar}$ & $6.4^{\circ} \mathrm{C}$ & 0 & 2017 \\
$\mathbf{R 4 0 7 F}$ & $\mathrm{A} 1$ & $-46.3^{\circ} \mathrm{C}$ & $82.7^{\circ} \mathrm{C}$ & $47.5 \mathrm{bar}$ & $6.4^{\circ} \mathrm{C}$ & 0 & 1824 \\
$\mathbf{L 4 0}$ & $\mathrm{A} 2 \mathrm{~L}^{\mathrm{a}}$ & $-44.7^{\circ} \mathrm{C}$ & $86.8^{\circ} \mathrm{C}$ & $47.3 \mathrm{bar}$ & $7.7^{\circ} \mathrm{C}$ & 0 & 285 \\
DR-7 & $\mathrm{A} 2 \mathrm{~L}^{\mathrm{a}}$ & $-43.3^{\circ} \mathrm{C}$ & $69.1^{\circ} \mathrm{C}$ & $45.5 \mathrm{bar}$ & $5.0^{\circ} \mathrm{C}$ & 0 & 246 \\
$\mathbf{N 4 0}$ & $\mathrm{A} 1^{\mathrm{a}}$ & $-45.1^{\circ} \mathrm{C}$ & $83.2^{\circ} \mathrm{C}$ & $44.5 \mathrm{bar}$ & $6.1^{\circ} \mathrm{C}$ & 0 & 1205 \\
DR-33 & $\mathrm{A} 1^{\mathrm{a}}$ & $-44.3^{\circ} \mathrm{C}$ & $83.1^{\circ} \mathrm{C}$ & 43.1 bar & $6.0^{\circ} \mathrm{C}$ & 0 & 1410 \\
\hline
\end{tabular}

${ }^{a}$ estimated safety group rating

${ }^{\mathrm{b}}$ pressure $=1 \mathrm{bar}$ 
Table 2. $\% \dot{V}_{\text {suc,LP }}$ Theoretical results.

\begin{tabular}{|c|c|c|c|c|c|}
\hline & & \multicolumn{2}{|c|}{$T_{o}=-40^{\circ} \mathrm{C}$} & \multicolumn{2}{|c|}{$T_{o}=-10^{\circ} \mathrm{C}$} \\
\hline & & $T_{k}=40^{\circ} \mathrm{C}$ & $T_{k}=55^{\circ} \mathrm{C}$ & $T_{k}=40^{\circ} \mathrm{C}$ & $T_{k}=55^{\circ} \mathrm{C}$ \\
\hline \multirow{6}{*}{ BC } & R407A & $3.52 \%$ & $-6.82 \%$ & $-0.07 \%$ & $-7.18 \%$ \\
\hline & R407F & $-4.88 \%$ & $-16.18 \%$ & $-6.23 \%$ & $-14.19 \%$ \\
\hline & $\mathbf{L 4 0}$ & $1.78 \%$ & $-12.61 \%$ & $3.04 \%$ & $-7.72 \%$ \\
\hline & DR-7 & $5.02 \%$ & $-8.39 \%$ & $4.95 \%$ & $-4.94 \%$ \\
\hline & N40 & $1.54 \%$ & $-9.48 \%$ & $0.90 \%$ & $-6.97 \%$ \\
\hline & DR-33 & $4.90 \%$ & $-6.54 \%$ & $3.56 \%$ & $-4.61 \%$ \\
\hline \multirow{6}{*}{ BCIHX } & R407A & $8.44 \%$ & $2.05 \%$ & $2.14 \%$ & $-2.74 \%$ \\
\hline & R407F & $0.85 \%$ & $-6.29 \%$ & $-3.58 \%$ & $-9.09 \%$ \\
\hline & L40 & $8.80 \%$ & $-0.77 \%$ & $6.38 \%$ & $-1.34 \%$ \\
\hline & DR-7 & $11.16 \%$ & $2.33 \%$ & $7.82 \%$ & $0.71 \%$ \\
\hline & N40 & $6.67 \%$ & $-0.29 \%$ & $3.29 \%$ & $-2.21 \%$ \\
\hline & DR-33 & $10.12 \%$ & $2.86 \%$ & $5.96 \%$ & $0.23 \%$ \\
\hline \multirow{6}{*}{ SC } & R407A & $12.65 \%$ & $10.15 \%$ & $4.14 \%$ & $1.63 \%$ \\
\hline & R407F & $5.98 \%$ & $3.11 \%$ & $-1.16 \%$ & $-4.05 \%$ \\
\hline & L40 & $16.68 \%$ & $12.79 \%$ & $10.28 \%$ & $6.25 \%$ \\
\hline & DR-7 & $18.56 \%$ & $15.12 \%$ & $11.76 \%$ & $8.18 \%$ \\
\hline & $\mathbf{N 4 0}$ & $11.85 \%$ & $9.15 \%$ & $5.80 \%$ & $3.00 \%$ \\
\hline & DR-33 & $15.58 \%$ & $12.78 \%$ & $8.68 \%$ & $5.78 \%$ \\
\hline
\end{tabular}


Table 3. $\% \dot{V}_{\text {suc,HP }}$ Theoretical results.

\begin{tabular}{|c|c|c|c|c|c|}
\hline & & \multicolumn{2}{|c|}{$T_{o}=-40^{\circ} \mathrm{C}$} & \multicolumn{2}{|c|}{$T_{o}=-10^{\circ} \mathrm{C}$} \\
\hline & & $T_{k}=40^{\circ} \mathrm{C}$ & $T_{k}=55^{\circ} \mathrm{C}$ & $T_{k}=40^{\circ} \mathrm{C}$ & $T_{k}=55^{\circ} \mathrm{C}$ \\
\hline \multirow{6}{*}{ DI } & R407A & $-6.04 \%$ & $-4.96 \%$ & $-15.80 \%$ & $-11.94 \%$ \\
\hline & R407F & $-13.50 \%$ & $-10.81 \%$ & $-24.09 \%$ & $-18.56 \%$ \\
\hline & L40 & $-6.67 \%$ & $-1.91 \%$ & $-20.14 \%$ & $-12.21 \%$ \\
\hline & DR-7 & $-1.07 \%$ & $2.47 \%$ & $-13.95 \%$ & $-7.21 \%$ \\
\hline & N40 & $-6.00 \%$ & $-3.30 \%$ & $-16.49 \%$ & $-10.97 \%$ \\
\hline & DR-33 & $3.60 \%$ & $1.43 \%$ & $0.82 \%$ & $-1.34 \%$ \\
\hline \multirow{6}{*}{ SC } & R407A & $2.29 \%$ & $-0.92 \%$ & $-0.35 \%$ & $-3.50 \%$ \\
\hline & R407F & $-3.57 \%$ & $-5.96 \%$ & $-6.49 \%$ & $-8.86 \%$ \\
\hline & L40 & $7.06 \%$ & $5.03 \%$ & $3.25 \%$ & $1.19 \%$ \\
\hline & DR-7 & $11.74 \%$ & $9.17 \%$ & $8.30 \%$ & $5.70 \%$ \\
\hline & N40 & $-3.06 \%$ & $-0.63 \%$ & $-13.96 \%$ & $-8.62 \%$ \\
\hline & DR-33 & $6.86 \%$ & $4.32 \%$ & $3.96 \%$ & $1.43 \%$ \\
\hline
\end{tabular}


Table 4. $\%$ COP Theoretical results.

\begin{tabular}{|c|c|c|c|c|c|}
\hline & & \multicolumn{2}{|c|}{$T_{o}=-40^{\circ} \mathrm{C}$} & \multicolumn{2}{|c|}{$T_{o}=-10^{\circ} \mathrm{C}$} \\
\hline & & $T_{k}=40^{\circ} \mathrm{C}$ & $T_{k}=55^{\circ} \mathrm{C}$ & $T_{k}=40^{\circ} \mathrm{C}$ & $T_{k}=55^{\circ} \mathrm{C}$ \\
\hline \multirow{6}{*}{ BC } & R407A & $9.02 \%$ & $20.52 \%$ & $4.53 \%$ & $12.14 \%$ \\
\hline & R407F & $10.62 \%$ & $24.45 \%$ & $4.93 \%$ & $13.83 \%$ \\
\hline & L40 & $15.07 \%$ & $32.60 \%$ & $7.45 \%$ & $18.92 \%$ \\
\hline & DR-7 & $15.09 \%$ & $30.76 \%$ & $9.94 \%$ & $20.13 \%$ \\
\hline & N40 & $11.31 \%$ & $24.05 \%$ & $5.79 \%$ & $14.18 \%$ \\
\hline & DR-33 & $11.87 \%$ & $24.78 \%$ & $6.56 \%$ & $15.09 \%$ \\
\hline \multirow{6}{*}{ BCIHX } & R407A & $4.80 \%$ & $11.20 \%$ & $2.68 \%$ & $7.84 \%$ \\
\hline & R407F & $5.25 \%$ & $12.82 \%$ & $2.58 \%$ & $8.48 \%$ \\
\hline & L40 & $8.69 \%$ & $18.50 \%$ & $4.70 \%$ & $12.47 \%$ \\
\hline & DR-7 & $9.65 \%$ & $18.55 \%$ & $7.56 \%$ & $14.46 \%$ \\
\hline & N40 & $6.71 \%$ & $13.83 \%$ & $3.79 \%$ & $9.49 \%$ \\
\hline & DR-33 & $7.32 \%$ & $14.60 \%$ & $4.59 \%$ & $10.42 \%$ \\
\hline \multirow{6}{*}{ DI } & R407A & $9.36 \%$ & $20.84 \%$ & $4.72 \%$ & $12.30 \%$ \\
\hline & R407F & $11.27 \%$ & $25.10 \%$ & $5.31 \%$ & $14.17 \%$ \\
\hline & L40 & $16.08 \%$ & $33.91 \%$ & $8.01 \%$ & $19.57 \%$ \\
\hline & DR-7 & $15.74 \%$ & $31.67 \%$ & $10.28 \%$ & $20.55 \%$ \\
\hline & N40 & $11.75 \%$ & $24.57 \%$ & $6.02 \%$ & $14.41 \%$ \\
\hline & DR-33 & $12.29 \%$ & $25.31 \%$ & $6.77 \%$ & $15.33 \%$ \\
\hline \multirow{6}{*}{ SC } & R407A & $4.01 \%$ & $8.91 \%$ & $2.31 \%$ & $6.52 \%$ \\
\hline & R407F & $4.42 \%$ & $10.12 \%$ & $2.25 \%$ & $7.01 \%$ \\
\hline & L40 & $7.23 \%$ & $14.70 \%$ & $4.01 \%$ & $10.31 \%$ \\
\hline & DR-7 & $7.87 \%$ & $14.61 \%$ & $6.50 \%$ & $11.97 \%$ \\
\hline & N40 & $5.58 \%$ & $11.02 \%$ & $3.25 \%$ & $7.87 \%$ \\
\hline & DR-33 & $6.08 \%$ & $11.64 \%$ & $3.94 \%$ & $8.65 \%$ \\
\hline
\end{tabular}

